This item was submitted to Loughborough's Research Repository by the author.

Items in Figshare are protected by copyright, with all rights reserved, unless otherwise indicated.

\title{
Nanofiltration of organic solvents
}

PLEASE CITE THE PUBLISHED VERSION

PUBLISHER

(C) Elsevier

VERSION

AM (Accepted Manuscript)

LICENCE

CC BY-NC-ND 4.0

REPOSITORY RECORD

Robinson, J.P., E.S. Tarleton, C.R. Millington, and Arian Nijmeijer. 2009. "Nanofiltration of Organic Solvents". figshare. https://hdl.handle.net/2134/5245. 
This item was submitted to Loughborough's Institutional Repository (https://dspace.lboro.ac.uk/) by the author and is made available under the following Creative Commons Licence conditions.

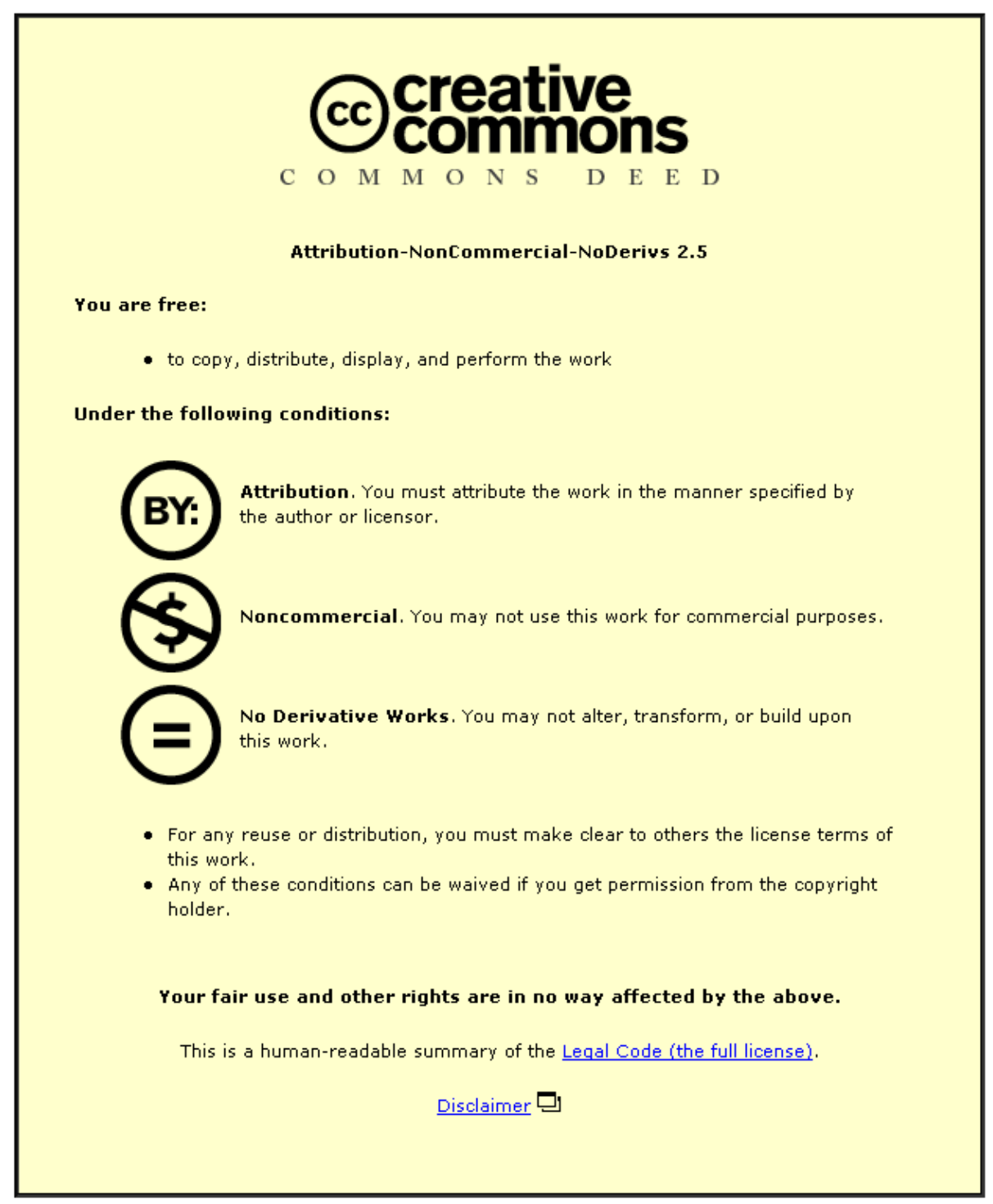

For the full text of this licence, please go to: http://creativecommons.org/licenses/by-nc-nd/2.5/ 


\title{
NANOFILTRATION OF ORGANIC SOLVENTS
}

\author{
J.P. Robinson ${ }^{1}$, E.S. Tarleton ${ }^{1}$ (e.s.tarleton@lboro.ac.uk), C.R. Millington ${ }^{2}$ and A. Nijmeijer ${ }^{3}$ \\ ${ }^{1}$ Advanced Separation Technologies Group, Department of Chemical Engineering, Loughborough \\ University, Loughborough, LE11 3TU, UK. \\ ${ }^{2}$ Shell Global Solutions, Cheshire Innovation Park, P.O. Box 1, Chester CH1 3SH, UK. \\ ${ }^{3}$ Shell Global Solutions International BV, P.O. Box 38000, 1030 BN Amsterdam, The Netherlands.
}

This article provides an insight into the mechanisms affecting solvent flux through dense membranes, and forms a basis for rejection studies of organic solute compounds from organic solvents.

\begin{abstract}
Transport mechanisms and process limitations are relatively well understood for aqueous nanofiltration systems. Much work has also been done on the use of membranes for the removal of suspended matter from organic solvents. The removal of organic solute compounds from organic solvents using membrane technology has been addressed by very few workers, and little is known of the fundamental transport and separation mechanisms.
\end{abstract}

The work aims to enhance the understanding of non-aqueous nanofiltration by focusing on the flux performance of organic solvents through a dense $2 \mu \mathrm{m}$ polydimethylsiloxane composite membrane. The flux of alcohols, n-alkanes, i-alkanes and cyclic compounds were studied in deadend mode, at pressures of $10-900 \mathrm{kPa}$. Fluxes of $10-80 \mathrm{l} / \mathrm{m}^{2} \mathrm{~h}$ were obtained for alkanes and cyclic compounds, whereas alcohol flux was around two orders of magnitude lower. The results suggest that the solvent flux through polydimethylsiloxane takes place via two distinct mechanisms - namely hydraulic and chemical transport. Hydraulic transport appears to dominate at pressures above $300 \mathrm{kPa}$, whereas chemical transport becomes more apparent at lower pressures.

Comparison of the hydraulic transport data with a Hagen-Poisuelle model gives good agreement for similar solvents. Swelling effects caused by solvent-membrane interactions are identified as playing a major role in solvent flux behaviour, and compressibility effects are also thought to account for deviations from the Hagen-Poisuelle model. Viscous flow was verified by a nonseparation of mixtures of $n$-alkane and cyclic compounds, which suggests that the polydimethylsiloxane layer cannot sustain a dense structure when used in organic solvent nanofiltration applications.

\section{INTRODUCTION}

Polydimethylsiloxane (PDMS) membranes are dense materials used in pervaporation, vapour permeation and gas separation processes. Recently, a number of workers have evaluated PDMS and other dense membranes for use in non-aqueous nanofiltration applications such as homogeneous catalyst recovery and the de-acidification of vegetable oils. Here we aim to enhance the understanding of the fundamental transport processes in non-aqueous nanofiltration with dense polymeric membranes.

\section{Previously Attempted}

Researchers have studied and previously attempted to model the behaviour of organic solvents and polymeric membranes. Initial development of thermodynamic theories was carried out by Paul and Ebra-Lima [1] as early as 1970, whereas studies of polymer-solvent interactions were documented by Flory [2] in the 1950s, and other workers since [3,4]. Two distinct processes have 
been reported for different membranes and operating regimes - namely physical and chemical transport.

\section{Physical Transport}

According to Darcy's Law, physical or hydraulic transport through membranes and other media with physical pores is pressure-driven. For liquids, the flux behaviour can be described by the Hagen-Poisuelle equation for viscous flow:

$$
J=\left(\frac{\varepsilon r^{2}}{8 L T}\right)\left(\frac{\Delta P}{\mu}\right)
$$

where $J$ is the solvent flux, $\varepsilon$ the porosity, $r$ the average pore radius, $\Delta P$ the differential pressure across the membrane, $\mu$ the liquid viscosity, $L$ the membrane thickness and $\tau$ the tortuosity factor. Pore tortuosity $\tau$ is usually defined as the ratio of the true length of the flow path and the straightline distance between the beginning and end points [5]. In many cases the pore geometry and geometry distribution is unknown, so the tortuosity factor reduces to an adjustable parameter.

For non-aqueous systems, possible interactions between the solvent and polymeric membranes have lead to the development of alternative transport equations. Machado et al. [6] proposed a resistance-in-series model to describe the flux of organic solvents through composite polymeric membranes. Three significant resistances to mass transport were identified as viscous flow in the membrane top layer, viscous flow in the porous support and hydrophilic/hydrophobic resistances. The resulting equation for solvent flux is:

$$
J=\frac{\Delta P}{\varphi\left[\left(\Delta \gamma+f_{1} \mu\right)+f_{2} \mu\right]}
$$

where $\varphi$ is a single parameter incorporating the membrane characteristics (porosity, tortuosity, thickness), $\Delta y$ is the surface energy difference between the membrane and solvent, and $f_{1}$ and $f_{2}$ are constants incorporating the individual mass transfer coefficients and pore radii. The model predicts that hydrophobicity plays an important role in solvent flux; polar solvents (those with a high surface tension) are expected to have a low flux through hydrophobic membranes, and a high flux through hydrophilic membranes. Zwijnenberg et al. [7] also report the importance of the surface energy difference in a study of polar and non-polar solvents with hydrophilic membranes.

Permeation through the membrane pores is only possible when the difference in surface energy can be overcome by the applied pressure. Bhanushali et al. [8] have shown that solvent surface tension is inversely proportional to flux for hydrophobic membranes, as polarity of organic solvents is strongly related to surface tension.

\section{Chemical Transport}

In pervaporation, gas separation and vapour permeation with dense membranes, chemical transport mechanisms are predominant. The favoured concept is that of the solution-diffusion model first proposed by Lonsdale et al. [9], where transport occurs by a substance dissolving in the membrane and diffusing through it. The separation potential of such a membrane is therefore determined by differences in solubility and diffusivity. An excellent review of the solution-diffusion model is given by Wijmans and Baker [10].

Many workers have studied sorption and diffusion behaviour of many solvents with PDMS membranes, with both sorption and diffusion being the main rate-determining step, depending on the solvent-polymer system. Sorption of solvents in polymers is non-ideal [11,12], that is, Henry's Law does not apply. The 'Hildebrand Solubility Parameter' $\delta$ is one method of estimating the 
affinity of a solvent for a particular polymer [13]. The parameter takes into account hydrogenbonding, polar and dispersive effects, and can be assigned to both solvents and polymers from their molecular structures and chemical groups. Solvents and polymers with a similar value of Hildebrand parameter would be expected to interact strongly, while those with dissimilar values would not. Such an approach has been verified by Bhanushali et al. [8], in a study of the sorption behaviour of a range of solvents in PDMS.

The diffusion of penetrant molecules through polymer networks can be ideal (Fickian) or non-ideal (non-Fickian). Substances with a low solubility in a membrane will generally exhibit Fickian diffusion, whereas high concentrations of penetrant will yield non-ideal behaviour [14]. Polymer networks can be described as being in a 'glassy' or 'rubbery' state. At temperatures below the glass-transition temperature $T_{g}$ polymers are in the glassy state and above $T_{g}$ they are in the rubbery state. Whether a membrane is in either state can also influence the diffusive behaviour of a penetrant, with the 'free volume' of rubbery polymers being an important factor [15].

In conclusion, literature suggests that the transport mechanisms for PDMS are dependent on the system operational parameters rather than the material itself. Gas separation, pervaporation and vapour permeation processes utilizing PDMS membranes are well described by the solutiondiffusion model, whereas the same membranes used for high-pressure solvent permeation processes are better modelled by Darcy's Law.

\section{EXPERIMENTAL}

\section{Materials}

The membranes used in this study were polyacrylonitrile PAN-PDMS composites supplied by GKSS Forschungszentrum. The nominal PDMS thickness was $2 \mu \mathrm{m}$, and an $\mathrm{O}_{2} / \mathrm{N}_{2}$ selectivity of 2.2 was reported for the membranes [16]. When received, the $\mathrm{N}_{2}$ permeance was checked and found to be $280 \pm 10$ barrer (see Nomenclature), assuming the nominal $2 \mu \mathrm{m}$ thickness to be correct. The $\mathrm{O}_{2} / \mathrm{N}_{2}$ selectivity and pure nitrogen permeation data confirmed that the selective layer in the membrane is PDMS [17].

\section{Thickness}

PDMS thickness was verified by SEM images of the membrane cross-section as shown in Figure 1. In order for the true cross-section to be viewed, the membrane was freeze-fractured to eliminate any effects of the cutting blade. Further SEM images of the membrane cross-section showed the thickness to be largely consistent at $2 \mu \mathrm{m}$, but variations between 1.5 and $3 \mu \mathrm{m}$ were noted in some places.

\section{Solvents}

The solvents used in this study were n-hexane, n-heptane, cyclohexane and xylene (mixture of isomers), supplied by Sigma-Aldrich Ltd. Methanol and ethanol were obtained from Fisher Scientific and isomeric alkanes were supplied by Shell Global Solutions. The exact compositions of the solvents were determined by gas-chromatography, and their densities and viscosities calculated from pure component data at $20^{\circ} \mathrm{C}$. The viscosity of mixtures was calculated using equation (3), an expression for mixtures of hydrocarbon liquids [18], where $\mu_{m}$ is the viscosity of the mixture, $\mu_{i}$ the individual component viscosity and $x_{i}$ the mole fraction.

$$
\mu_{m}=\left(\sum_{1}^{n} x_{i} \mu_{i}^{1 / 3}\right)^{3}
$$




\section{Test Apparatus}

Solvent flux was measured at pressures from 10 to $900 \mathrm{kPa}$. A schematic of the membrane module is shown in Figure 2. The module comprises two stainless steel discs $150 \mathrm{~mm}$ in diameter and $20 \mathrm{~mm}$ thick. The bottom plate was milled such that a $75 \mathrm{~mm}$ diameter sintered plate fitted flush with the top surface. The flat-sheet membrane was cut into a disc such that it overlapped the sintered plate by $10 \mathrm{~mm}$. A $3 \mathrm{~mm}$ thick polytetrafluoroethylene (PTFE) gasket was placed over the top to clamp the membrane in position, facilitate a hydraulic seal and provide a space between the membrane and top plate to be filled with liquid. Inlet and outlet channels on the top plate allowed the module to operate in both dead-end and crossflow modes.

The solvents were supplied to the module using the apparatus shown in Figure 3. Compressed nitrogen was used to pressurize the solvent in the reservoir. The solvent was then forced through a dip-tube out of the reservoir to the membrane module.

Pressures were measured using a gauge mounted in the solvent reservoir, which was calibrated at frequent intervals using a commercial Druck DPI 603 calibration apparatus. As all experiments reported in this article were carried out in dead-end mode. The pressure in the reservoir corresponds to that above the membrane surface.

\section{Experimental Method}

Before starting the permeation experiments, the valve on the membrane module outlet was opened fully, and a small pressure applied to the fluid in the reservoir to bleed any excess air from the system. Solvent $(100 \mathrm{ml})$ was then run through the module to remove any remaining gas and to flush away any residual solvent from the previous test. The module exit valve was then closed, and the pressure increased to the test pressure. The permeate was left to drain for 10 mins. to establish a steady-state before being collected in a narrow-necked flask. Experiments were given enough time to allow approximately $100 \mathrm{ml}$ of solvent to permeate the membrane. The permeation rate was measured by weighing the collected permeate after a specific time.

When transferring between different solvents, $500 \mathrm{ml}$ of the fresh solvent was run through the reservoir, and the module, to flush away any residue of the previous solvent.

\section{Repeatability}

Three PDMS membranes were used to obtain the results reported in this paper. The n-heptane flux between different membranes varied by $\pm 10 \%$ for those used here, and in other studies that have not yet been reported. The $n$-heptane flux through individual membranes varied by $\pm 2 \%$ over a period of several days. Interestingly, a $10 \%$ increase in flux was observed when a membrane was used for several weeks. Once the $n$-heptane flux had reached $110 \%$ of the initial readings, the membrane was replaced. Whether a membrane was stored in a swollen-state or allowed to dry had no noticeable impact on the flux performance.

To account for the different membranes and associated variability, the flux-pressure relationship for n-heptane was determined first. The n-heptane fluxes were also measured at 300, 600 and 900 $\mathrm{kPa}$ before the flux-pressure relationship of a new solvent was determined. Flux-pressure relationships were established at random pressure increments, with no effect of hysteresis. The ratio of solvent flux: $n$-heptane flux was calculated in each series of experiments, and that ratio was used to calculate the solvent flux based on the original $n$-heptane data. The recalculation based on that ratio enabled solvent fluxes to be accurately compared.

\section{RESULTS AND DISCUSSION}


Data presented here are representative; other similar data has been acquired to confirm.

The flux of alkanes and aromatic solvents ranged from $10-100 \mathrm{l} / \mathrm{m}^{2} \mathrm{~h}$, depending on solvent and pressure. Methanol and ethanol, however, had much lower fluxes. Alcohol flux could not be accurately quantified because the evaporation rate from the permeate collection beaker was significant compared with the flux. No further attempt was made to measure alcohol fluxes, instead it was estimated that the alcohol flux is around two orders of magnitude lower than that of alkanes.

Figure 4 shows typical flux measurements at pressures of 300-900 kPa for n-hexane and cyclohexane. Linear relationships were found between 300 and $900 \mathrm{kPa}$, however in all experiments the flux behaviour of n-alkane, i-alkane and cyclic solvents could be extrapolated to give a positive intercept on the $y$-axis. Table 1 shows gradients and intercepts of the flux-pressure relationships for all solvents in the $300-900 \mathrm{kPa}$ pressure range.

Two-part experiments were carried out with xylene and n-heptane. The flux-pressure relationship was established at $300-900 \mathrm{kPa}$, then the apparatus was modified to assess flux behaviour at pressures as low as $10 \mathrm{kPa}$. This was done by adding a second pressure regulator and pressure gauge with a range of $0-250 \mathrm{kPa}$. The results for xylene can be seen in Figure 5, where the deviation from the 300-900 kPa trend is shown. Figure 6 shows low and high pressure data for nheptane, with two distinct regions highlighted. It is shown that a linear flux-pressure relationship exists in both regions, with 300-350 kPa being the pressure range corresponding to the transition between the two regions.

\section{Positive Intercept}

To the knowledge of the authors the positive intercept for pressures above $300 \mathrm{kPa}$ has not been reported by other workers in the field. Bhanushali et al. [8] reported a zero intercept for various solvents and a PDMS membrane at pressures of 500-5000 kPa. Gibbins et al. [19] reported the steady-state methanol permeation through a STARMEM 122 membrane at pressures of 1000$6000 \mathrm{kPa}$ to have a zero intercept, whereas their results clearly show an intercept of around 20 $\mathrm{l} / \mathrm{m}^{2} \mathrm{~h}$. Scarpello et al. [20] studied solvent flux through a range of organic nanofiltration membranes at pressures of $1000-4000 \mathrm{kPa}$ and found a zero intercept. It is likely that positive intercepts have been overlooked because of the higher pressures studied by other workers. The lower pressures used in this study, combined with data obtained at pressure increments of 100 $\mathrm{kPa}$, serve to highlight the positive intercept not previously seen.

A $10 \mu \mathrm{m}$ sample of PDMS with the same PAN substrate was obtained, and the gradient and intercept of the flux-pressure relationship of $n$-heptane were found to be one-fifth of that obtained for the $2 \mu \mathrm{m}$ membrane. This result supports the concept of a positive intercept, and is thought to be because of solvent and membrane properties. No fault in the testing apparatus or test procedure could be identified, and many duplicate experiments confirmed the results shown.

\section{Flux-Pressure Relationships}

The distinct regions in the flux-pressure relationships for all solvents can potentially be explained in two ways. Linear and reversible compaction of the PDMS layer may take place at pressures up to $300 \mathrm{kPa}$, whence the membrane cannot be compressed further. Another explanation is that there are two distinct transport mechanisms - hydraulic and diffusive transport.

Since PDMS membranes have been found to allow diffusion of organic solvents in pervaporation and vapour permeation [21,22], it is reasonable to assume that such diffusive processes can occur in nanofiltration. The diffusion may be assisted by the hydraulic permeation, where positive intercepts correspond to the maximum rate of chemical transport through the PDMS layer. 
The alkane and aromatic solvents used in this study are non-polar, with a solubility parameter similar to that of PDMS. Sorption into the PDMS structure and subsequent diffusion through the membrane will therefore occur, however, desorption on the permeate side will be limited because of the high affinity of the solvent for the polymer.

An experiment was performed with no applied pressure, and only a $10 \mathrm{~cm}$ head of solvent corresponding to a pressure of $7 \mathrm{kPa}$. No detectable solvent flux was obtained under this mode of operation. It is thought that desorption can occur when solvent is present on the permeate side of the membrane, and thus chemical transport can be assisted by hydraulic permeation. As more solvent permeates by hydraulic flow (increased pressure), chemical transport is increased until the maximum rate of sorption/diffusion/desorption is reached which, in this case, may correspond to a pressure around $300 \mathrm{kPa}$. Above the $300 \mathrm{kPa}$ region, the rate of chemical transport is thought to be constant, and corresponds directly to the observed positive intercepts. Unfortunately, no swelling equilibrium data were available for the solvents and the PDMS membrane used in this study so calculations of diffusion coefficients are not possible.

Both explanations are speculative at this stage, and are intended as hypotheses for further study rather than definitive transport mechanisms.

\section{Hydraulic Mechanism}

It has been previously suggested that solvent transport takes place via a hydraulic (pressure driven) mechanism consistent with Darcy's Law and the Hagen-Poisuelle model [8]. Referring to equation (1), if solvent transport is consistent with the Hagen-Poisuelle model, then a plot of flux against $(\Delta P / \mu)$ for all solvents should yield one straight line with gradient $\left(\varepsilon r^{2} / 8 L T\right)$. Table 2 shows the densities and viscosities for the solvents used in this study, and Figure 7 shows the HagenPoisuelle plot for all solvents.

\section{Distinct Correlations}

Three distinct correlations can be identified. The n-alkanes and i-alkanes show different but consistent gradients, whereas the two cyclic compounds appear to lie on the same regression line, albeit with a higher gradient than that noted for the n-alkanes. It is clear that cyclohexane, a cyclic alkane, does not obey the same trend as the other alkanes, but it is not currently possible to determine whether the difference is solely down to molecular shape. It appears that apparently similar solvents affect their own membrane properties, that is, their own specific value of $\left(\varepsilon r^{2} / 8 L T\right)$. This is a somewhat surprising result because PDMS is a dense membrane with no defined porous structure, yet solvent families behave as if the membrane has pores. The specific gradients for each solvent type may be because of the unique swelling effects of different solvents. As indicated previously, the Hildebrand solubility parameter gives a reasonable indication of the swelling behaviour of various solvents, and the relationship between the Hagen-Poisuelle gradient $\left(\varepsilon r^{2} / 8 L T\right)$ and $\delta$ is shown in Figure 8.

Figure 8 shows that solvents with a higher value of Hildebrand parameter generally exhibit a higher Hagen-Poisuelle gradient, although the solvents studied have a limited range of $\delta$. Accurate permeation measurements of methanol and ethanol, along with other polar solvents such as acetone may provide a better indication of the dependence of Hagen-Poisuelle gradient with the degree of swelling. A more comprehensive study is desirable as it could ultimately lead to the prediction of solvent flux based on readily-available physical properties; viscosity and the Hildebrand solubility parameter.

\section{Compressibility}

Another possible explanation for the different gradients is that bulk viscosities may not be valid in high-pressure systems because of the compressibility of solvents. Such an explanation is 
suggested by Bowen and Welfoot [23], who investigated the behaviour of nanofiltration membranes with aqueous systems.

A study of the behaviour of solvent mixtures potentially gives a better insight into compressibility effects. The flux behaviour of two binary solvent systems was investigated. The two solvent systems were $n$-heptane/xylene and n-hexane/cyclohexane, chosen to illustrate the behaviour of cyclic/straight-chain mixtures. In both cases, the fluxes of the n-alkanes were higher than that of the cyclic compounds at equivalent pressures, and no separation of the solvent mixtures by the membrane occurred under this mode of operation. It is noted that mixtures were not analyzed for potential separation at pressures below $300 \mathrm{kPa}$. The flux behaviour of the two binary systems was modelled with the Hagen-Poisuelle equation as shown in Figures 9 and 10.

For both solvent systems studied, intermediate mixtures follow the same trend as for the cyclic compounds (cyclohexane and xylene), with the straight-chain alkanes lying outside the rest of the data. Since the chemistry of the cyclic compounds is quite different the effect is likely to be influenced in some way by their cyclic shape. It is speculated that pure straight-chain hydrocarbons are able to become more ordered when under compression and hence increase their viscosity. The cyclic shape of cyclohexane and xylene may make them more rigid, and not as compressible as straight chain species. Addition of cyclic compounds to n-alkanes may also prevent compressibility of the straight-chain species. This goes some way to explain why the Hagen-Poisuelle plots for heptane and hexane lie below those of cyclohexane and xylene. Viscosity increases of $10 \%$ for $n$-heptane and $30 \%$ for $n$-hexane would be required to produce the deviations shown in Figure 9 and Figure 10.

The compressibility hypothesis is speculative, although order of magnitude calculations show it to be potentially valid. Alternatively, the deviations may be caused by swelling effects. It is possible that the swelling behaviour of the solvent mixtures used in this study do not vary linearly with composition. Yoo et al. [4] demonstrated non-linear swelling behaviour with mixtures of $n$ hexane/acetone and n-hexane/ethanol in PDMS, although data for the binary solvent systems used in this study is currently unavailable.

\section{CONCLUSIONS}

It has been demonstrated for PDMS membranes that solvent transport may take place via two distinct transport mechanisms depending on trans-membrane pressure. At pressures above 300 $\mathrm{kPa}$ solvent transport is governed predominantly by hydraulic conditions, whereas below $300 \mathrm{kPa} a$ second mechanism is apparent which may involve sorption and diffusion.

The hydraulic transport of solvents gives good agreement with the Hagen-Poisuelle model, although different solvent species appear to affect their own membrane properties. Deviations from the Hagen-Poisuelle model are likely to be caused by swelling effects, although the limited range of solvents studied prevent a direct correlation.

The flux of binary solvent mixtures was investigated, and no separation occurred. Mixtures of cyclic and straight-chain solvents fitted the Hagen-Poisuelle model, although pure n-alkanes showed deviations from their respective mixtures. A compressibility hypothesis was proposed to account for such deviations, although swelling effects may also explain the flux behaviour of solvent mixtures.

\section{ACKNOWLEDGMENTS}


Shell Global Solutions (UK), is acknowledged for supplying the project funding, technical hardware and isomeric solvents. EPSRC is also acknowledged for part-funding this project. The PDMS membranes used in this study were kindly supplied by GKSS Forschungszentrum.

\section{NOMENCLATURE}

f constant $(\mathrm{m} / \mathrm{s})$

$J \quad$ solvent flux $\left(I / \mathrm{m}^{2} \mathrm{~h}\right)$

$K \quad$ permeability constant $\left(\mathrm{l} /\left(\mathrm{m}^{2} \mathrm{~h} \mathrm{~Pa}\right)\right)$

$L \quad$ membrane thickness $(\mathrm{m})$

$\Delta P \quad$ differential pressure $(\mathrm{Pa})$

$x \quad$ mole fraction

$\delta \quad$ solubility parameter $\left(\mathrm{MPa}^{1 / 2}\right)$

$\varepsilon \quad$ porosity

$\varphi \quad$ constant $\left(\mathrm{s} / \mathrm{m}^{2}\right)$

$V \quad$ surface tension $(\mathrm{N} / \mathrm{m})$

$\mu \quad$ viscosity (Pa s)

$T \quad$ tortuosity factor

barrer $\times 10^{-10} \mathrm{~cm}^{3}(\mathrm{STP}) . \mathrm{cm} / \mathrm{cm}^{2} \mathrm{~s}(\mathrm{~cm} \mathrm{Hg})$

\section{REFERENCES}

1. D.R. Paul and O.M. Ebra-Lima: Pressure induced diffusion of organic liquids through highly swollen polymer membranes, J. App. Poly. Sci. 14 (1970) 2201-2224.

2. P.J. Flory: Principles of polymer chemistry (Cornell University Press, USA, 1953).

3. Y-.M. Sun and J. Chen: Sorption/desorption properties of ethanol, toluene and xylene in poly (dimethylsiloxane) membranes, J. App. Poly. Sci. 51 (1994) 1797-1804.

4. J.S. Yoo, S.J. Kim and J.S. Choi: Swelling equilibria of mixed solvent/poly(dimethylsiloxane) systems, J. Chem. Eng. Data 44 (1999) 16-22.

5. M. Sahimi: Flow and transport in porous media and fractured rock (VCH, 1995).

6. D.R. Machado, D. Hasson and R. Semiat: Effect of solvent properties on permeate flow through nanofiltration membranes. Part II: Transport model, J. Membrane Sci. 166 (2000) 6369.

7. H.J. Zwijnenberg, A.M. Krosse, K. Ebert, K.-V. Peinemann and F.P. Cuperus: Acetone-stable nanofiltration membranes in deacidifying vegetable oil, J. Am. Oil. Chem. Soc. 76 (1999) 8387.

8. D. Bhanushali, S. Kloos, C. Kurth and D. Bhattacharyya: Performance of solvent-resistant membranes for non-aqueous systems: Solvent permeation results and modelling, J. Membrane Sci. 189 (2001) 1-21.

9. H. Lonsdale, U. Merten and R. Riley: Transport of cellulose acetate osmotic membranes, J. Appl. Polym. Sci. 9 (1965) 1341.

10. J.G. Wijmans and R.W. Baker: The solution-diffusion model: A review, J. Membrane Sci. 107 (1995) 1-21. 
11. Y-M. Sun and J. Chen: Sorption/desorption properties of ethanol, toluene and xylene in poly(dimethylsiloxane) membranes, J. App. Poly. Sci. 51 (1994) 1797-1804.

12. E. Favre, P. Schaetzel, Q.T. Nguygen, R. Clement and J. Neel: Sorption, diffusion and vapour permeation of various penetrants through dense poly(dimethylsiloxane) membranes: A transport analysis, J. Membrane Sci. 92 (1994) 169-184.

13. A.F.M. Barton: CRC handbook of solubility parameters and other cohesion parameters (CRC Press, 1983).

14. J.S. Vrentas, J.L. Duda and W.J. Huang: Regions of Fickian diffusion in polymer-solvent systems, Macromol. 19 (1986) 1718-1724.

15. J.L. Duda and J.M. Zielinski: Free-volume theory, in: P. Neogi (Ed.): Diffusion in polymers (Marcel Dekker, 1996), Chapter 3.

16. GKSS Forschungszentrum, Technical Datasheet, October 2001.

17. M.H.V. Mulder: Basic principles of membrane technology (Kluwer Academic Publishers, 1991).

18. R.H. Perry and D.W. Green (Eds.): Perry's chemical engineers handbook, $7^{\text {th }}$ Edn. (McGrawHill, 1998) 2-367.

19. E. Gibbins, M. D'Antonio, D. Nair, L.S. White, L.M. Freitas dos Santos, I.F.J. Vankelecom and A.G. Livingston: Observations on solvent flux and solute rejection across solvent resistant nanofiltration membranes, Desalination 147 (2002) 307-313.

20. J.T. Scarpello, D. Nair, L.M. Freitas dos Santos, L.S. White and A.G. Livingston: The separation of homogeneous organometallic catalysts using solvent resistant nanofiltration, $J$. Membrane Sci. 203 (2002) 71-85.

21. H.-K. Oh, K.-H. Song, K.-R. Lee and J.-M. Rim: Prediction of sorption and flux of solvents through PDMS membrane, Polymer 42 (2001) 6305-6312.

22. C.K. Yeom, S.H. Lee, H.Y. Song and J.M. Lee: Vapor permeations of a series of $\mathrm{VOC} / \mathrm{N}_{2}$ mixtures through PDMS membranes, J. Membrane Sci. 198 (2002) 129-143.

23. W.R. Bowen and J.S. Welfoot: Modelling the performance of membrane nanofiltration - Critical assessment and model development, Chem. Eng. Sci. 57 (2002) 1121-1137. 
FIGURES AND TABLES

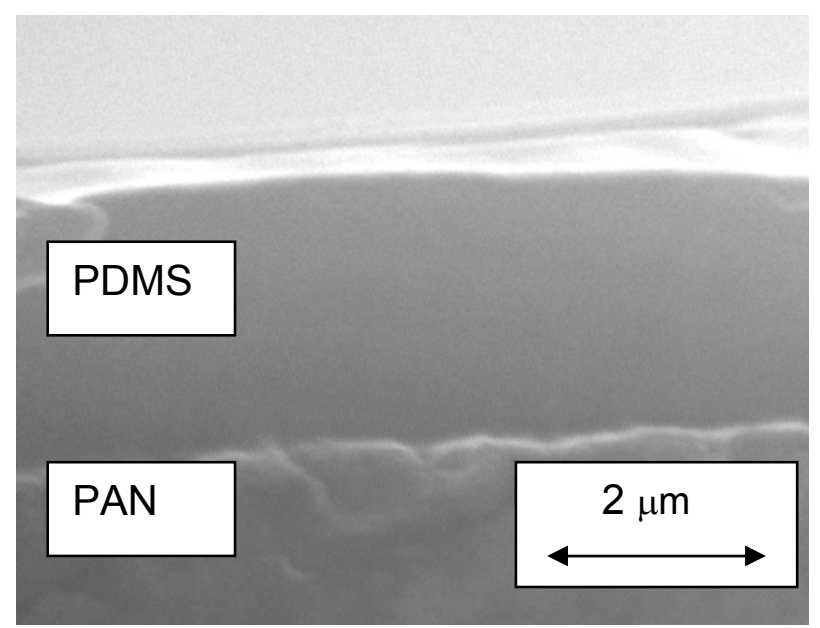

Figure 1: 20 kV SEM cross-section image showing a $2 \mu \mathrm{m}$ PDMS layer on the PAN substrate.

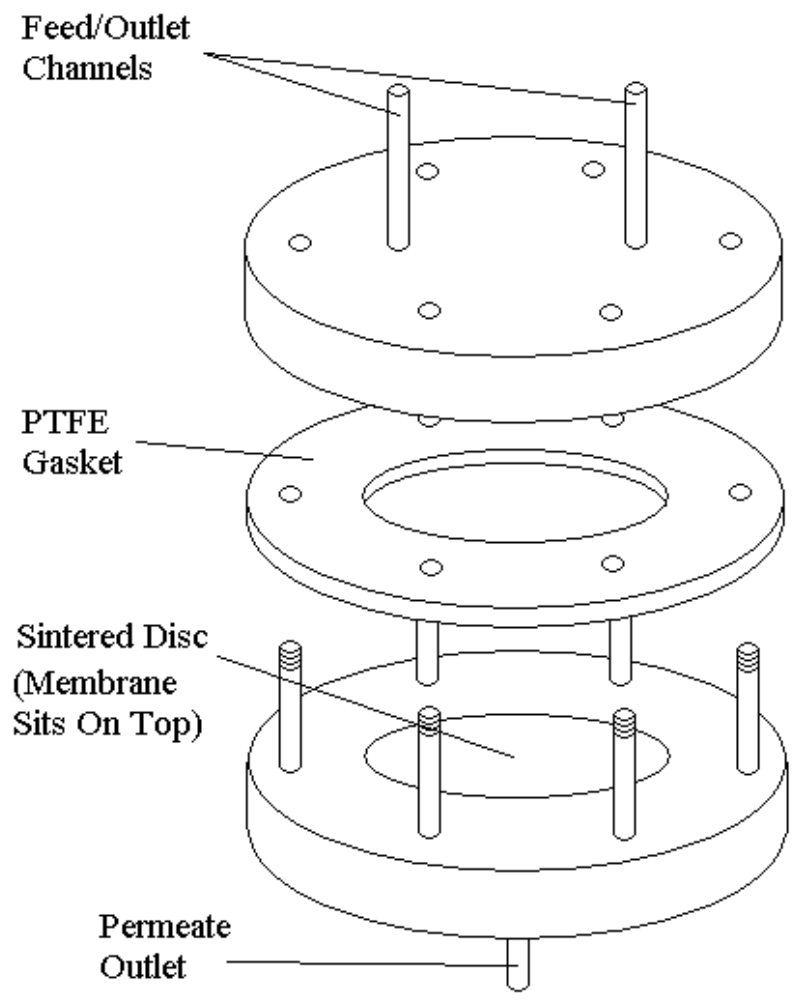

Figure 2: Schematic of the flat-sheet membrane module. 


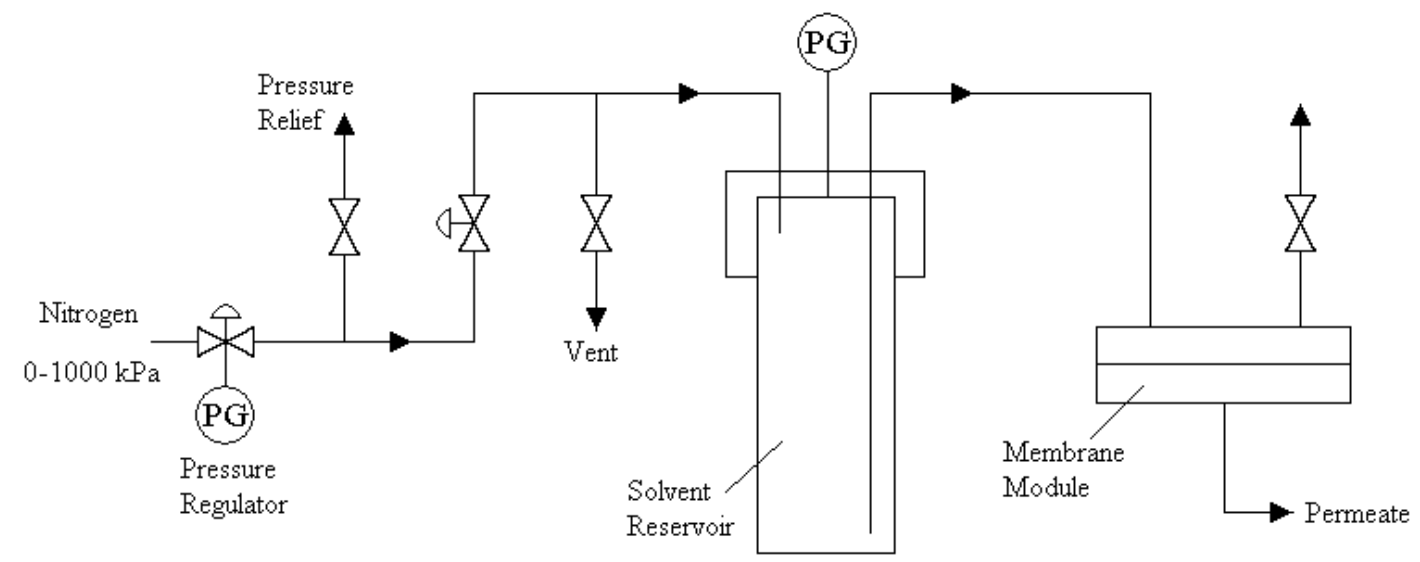

Figure 3: Schematic of solvent permeation apparatus.

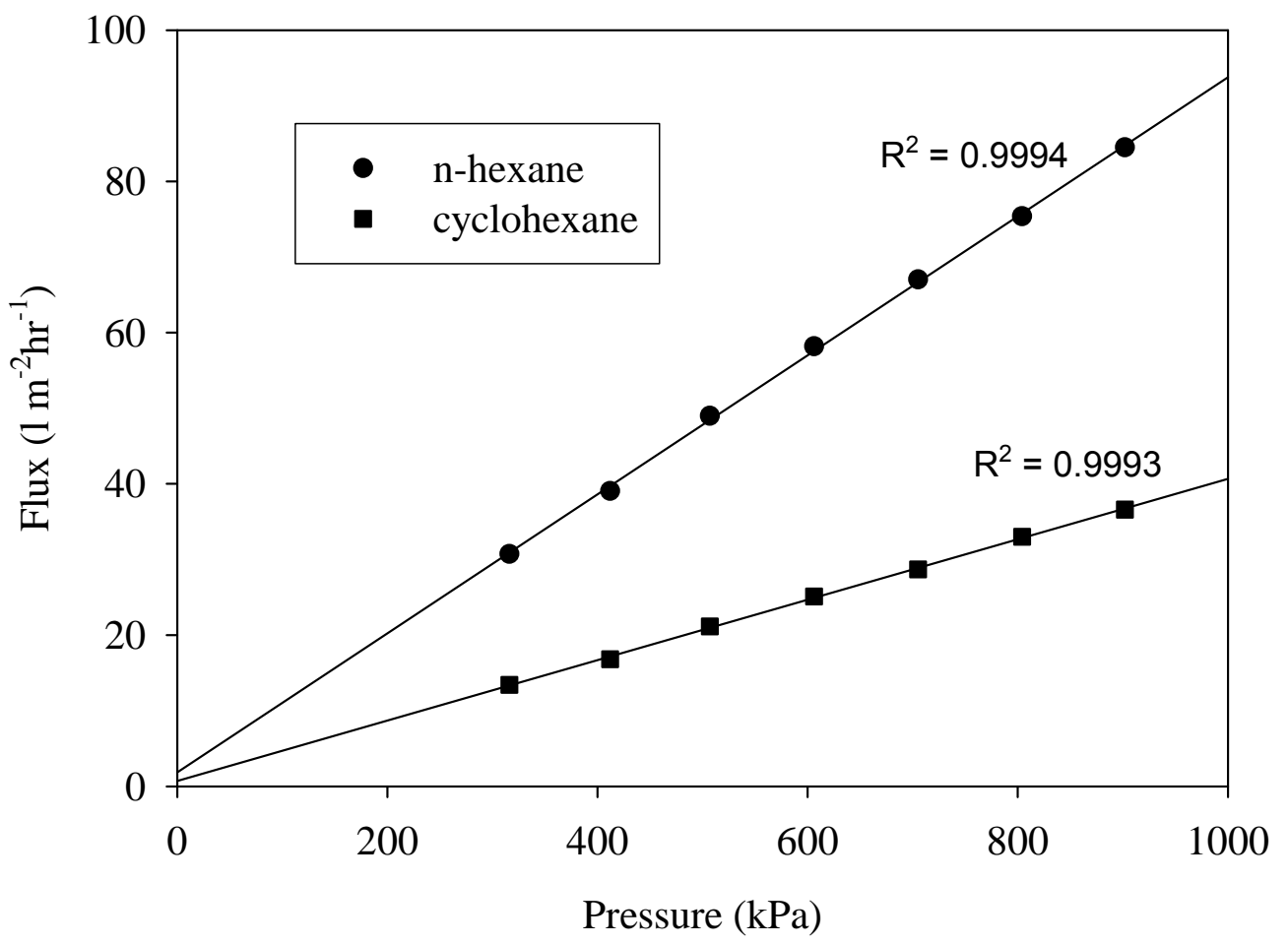

Figure 4: Flux-pressure relationship for n-hexane and cyclohexane. 


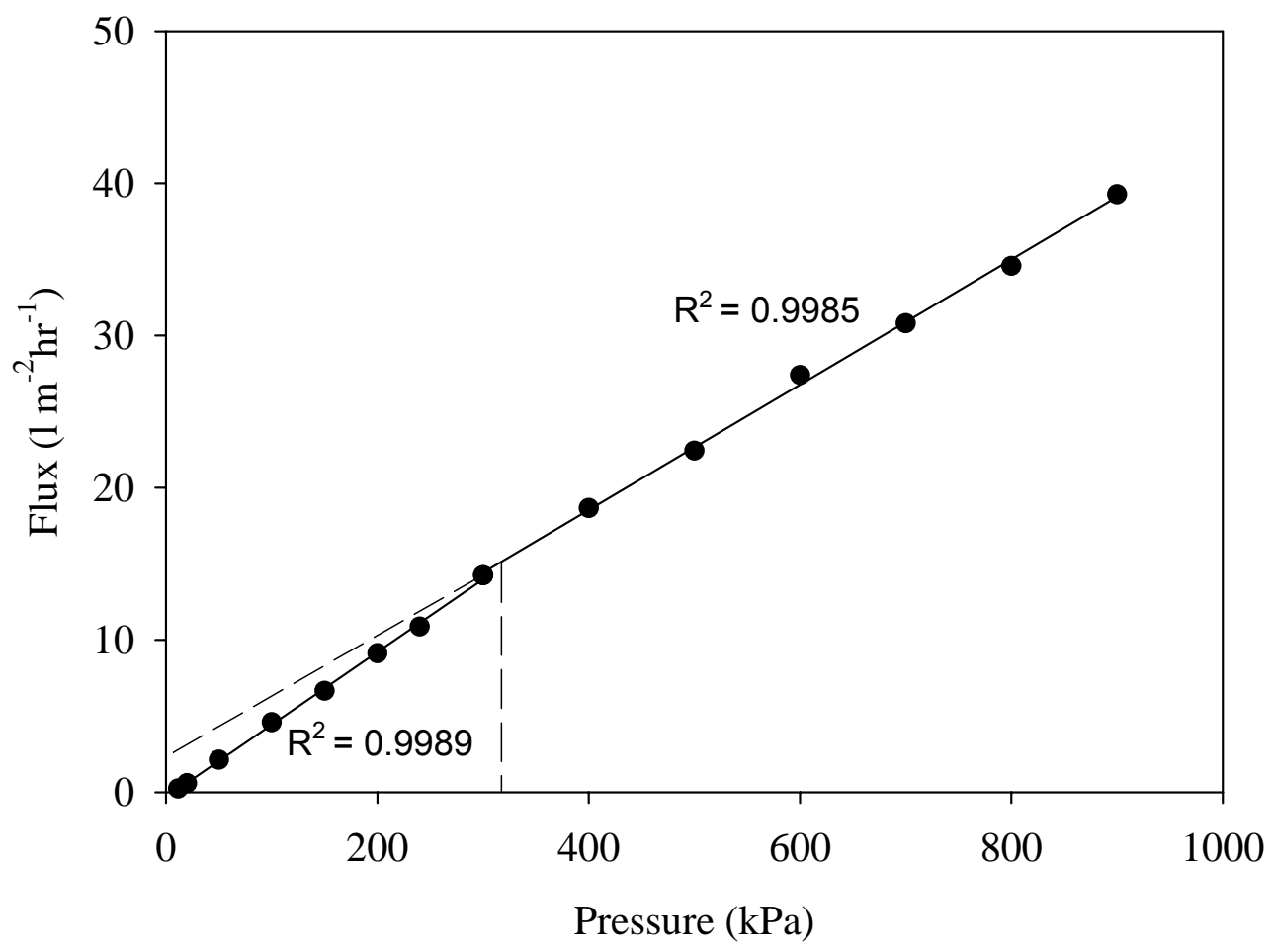

Figure 5: Flux-pressure relationship for xylene at high and low pressures.

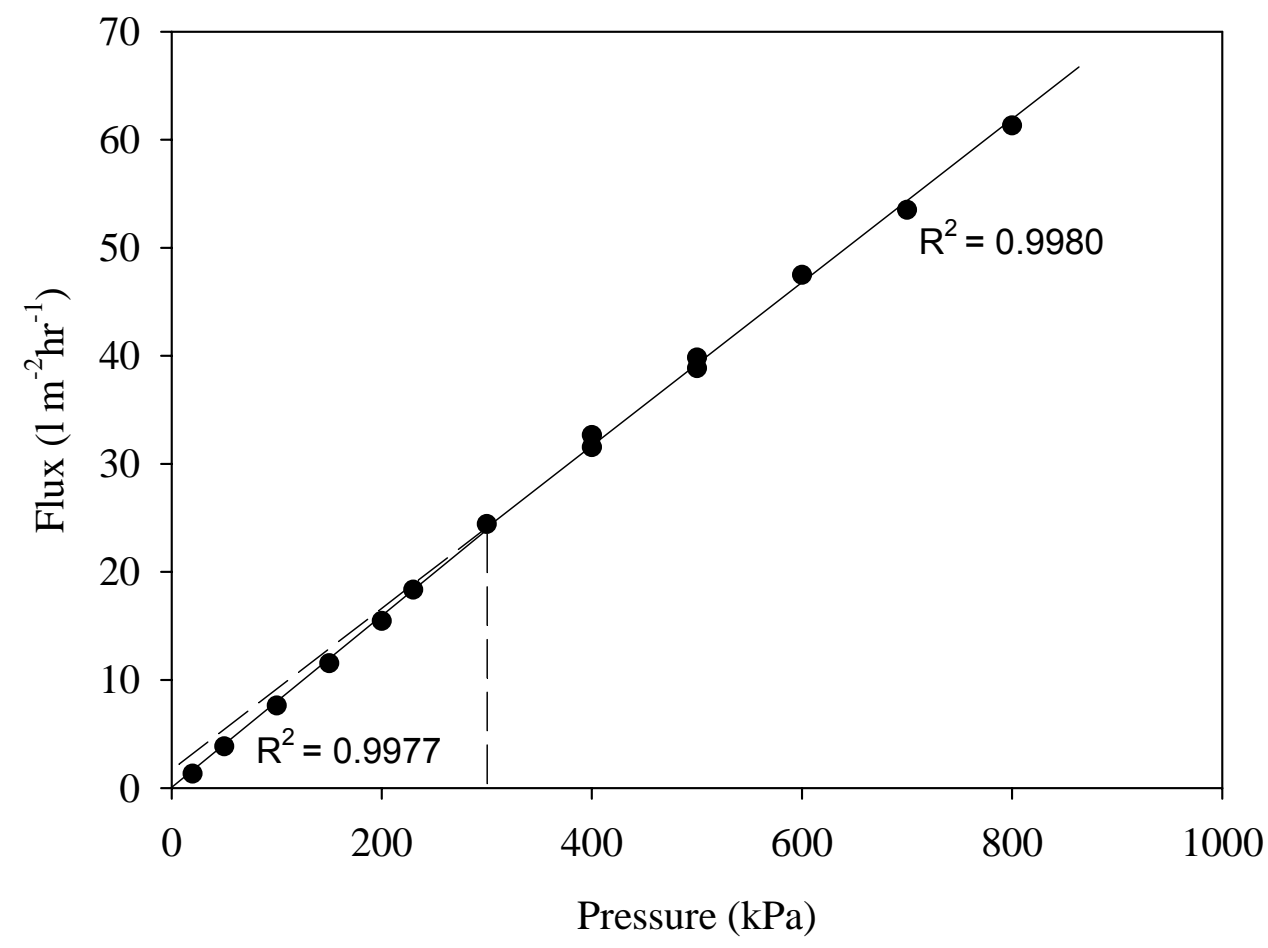

Figure 6: Flux-pressure relationship for n-heptane at high and low pressures. 


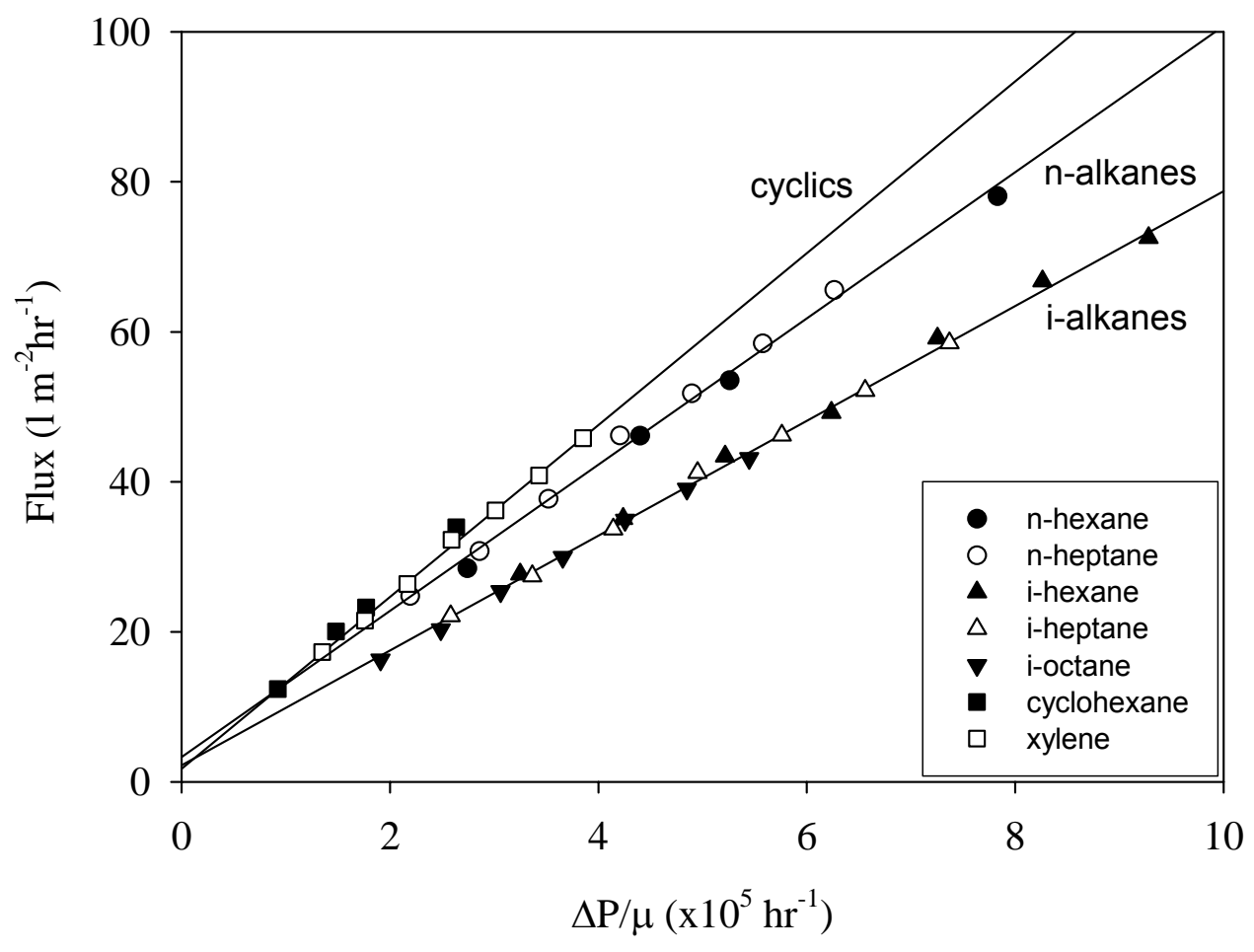

Figure 7: Application of Hagen-Poisuelle model for all solvents tested.

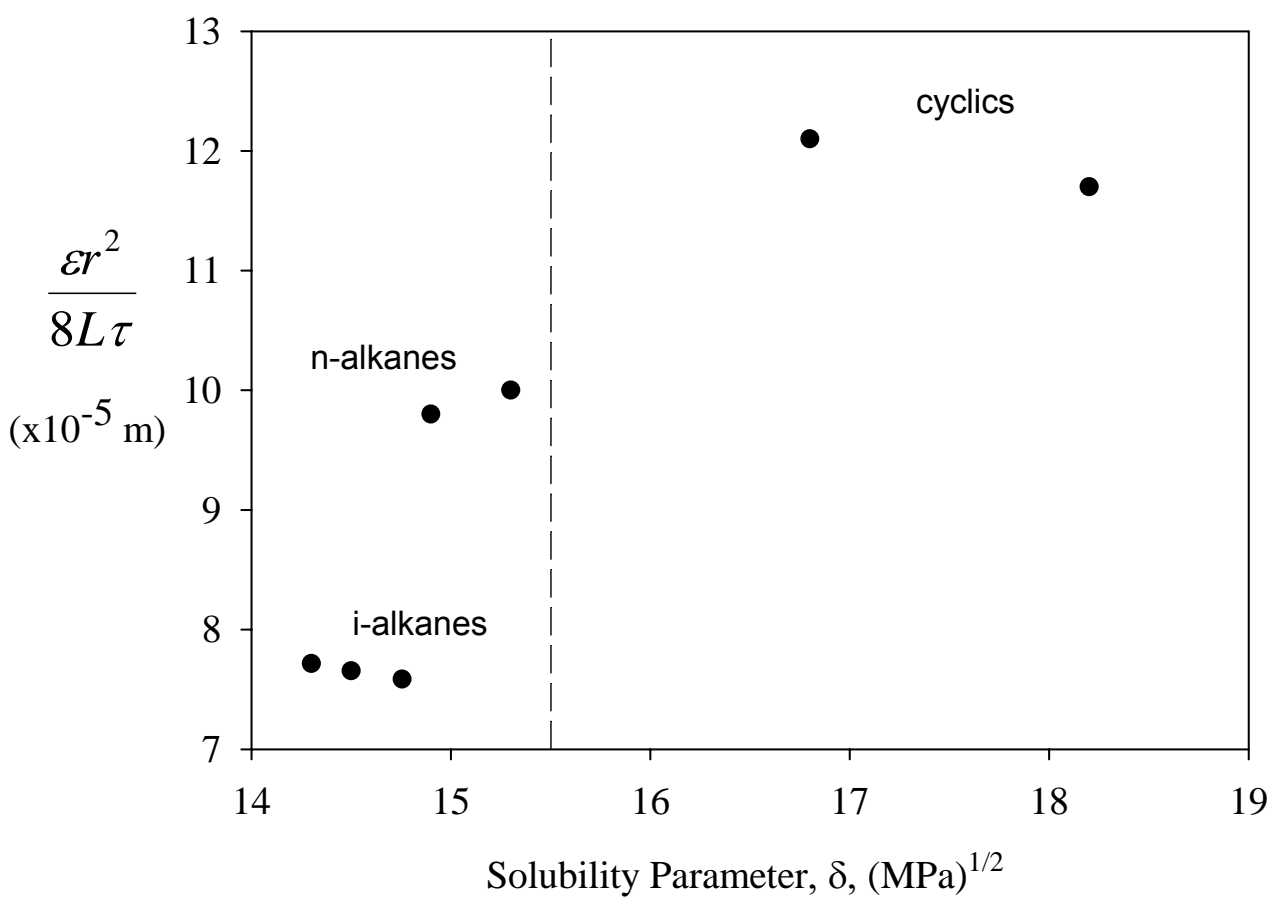

Figure 8: Effect of swelling on the gradient of the Hagen-Poisuelle plot. The dotted line represents the solubility parameter of PDMS, $15.5 \mathrm{MPa}^{0.5}$. Values of $\delta$ are taken from [12]. 


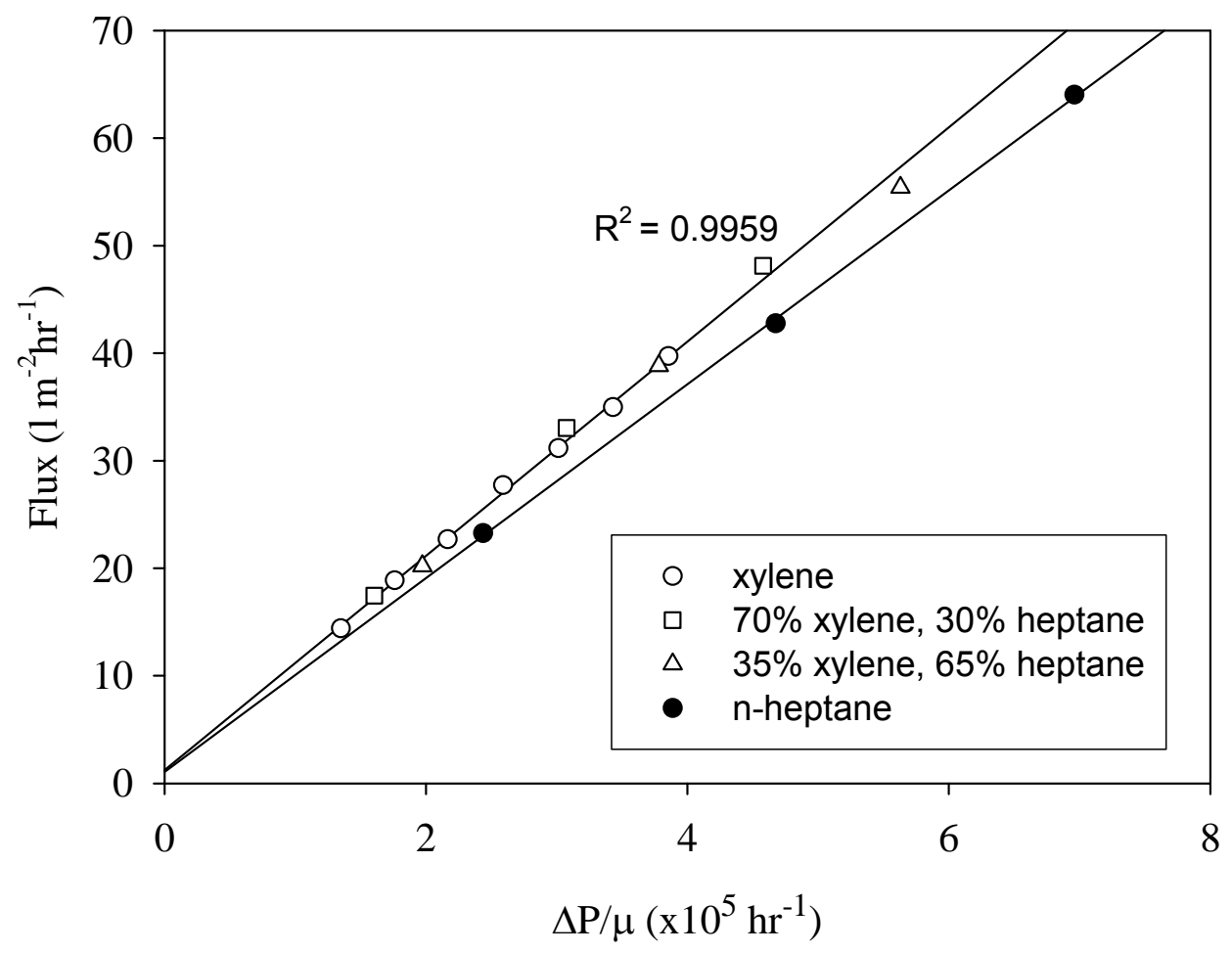

Figure 9: Hagen-Poisuelle model for the xylene/n-heptane binary solvent system. $R^{2}$ value calculated with n-heptane data omitted.

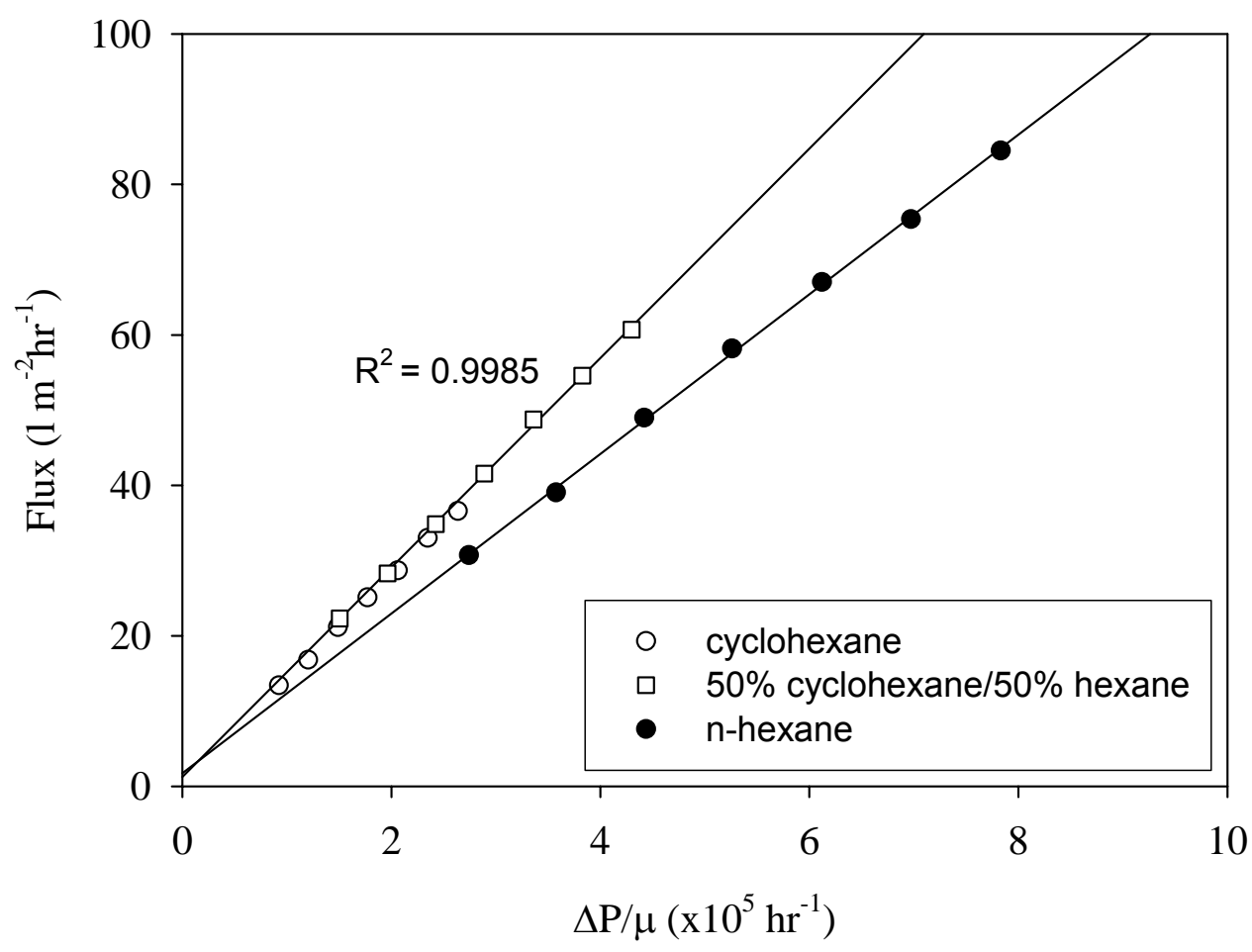

Figure 10: Hagen-Poisuelle model for the $n$-hexane/cyclohexane binary solvent system. $R^{2}$ value calculated with n-hexane data omitted. 


\begin{tabular}{|l|c|c|}
\hline Solvent & $\begin{array}{c}\text { Gradient } \\
\left(\times 10^{-2} \mathrm{I} /\left(\mathrm{m}^{2} \mathrm{~h} \mathrm{kPa}\right)\right)\end{array}$ & $\begin{array}{c}\text { Intercept } \\
\left(\mathrm{I} / \mathrm{m}^{2} \mathrm{~h}\right)\end{array}$ \\
\hline n-hexane & 8.41 & 2.53 \\
n-heptane & 7.00 & 2.49 \\
i-hexane & 7.80 & 3.17 \\
i-heptane & 6.25 & 2.23 \\
i-octane & 4.66 & 1.56 \\
cyclohexane & 3.66 & 1.10 \\
xylene & 4.90 & 1.74 \\
\hline
\end{tabular}

Table 1: Gradients and intercepts of the flux-pressure relationship in the $300-900 \mathrm{kPa}$ range.

\begin{tabular}{|l|c|c|c|}
\hline Classification & Solvent & $\begin{array}{c}\text { Density } \\
\left(\mathrm{kg} \mathrm{m}^{-3}\right)\end{array}$ & $\begin{array}{c}\text { Viscosity } \\
\left(\times 10^{-3} \mathrm{~Pa} \mathrm{~s}\right)\end{array}$ \\
\hline Straight-chain alkane & n-hexane & 660 & 0.32 \\
Branched alkane & n-heptane & 681 & 0.40 \\
& i-hexane & 653 & 0.27 \\
& i-heptane & 678 & 0.34 \\
Cyclic alkane & i-octane & 692 & 0.46 \\
Cyclic aromatic & cyclohexane & 779 & 0.95 \\
\hline
\end{tabular}

Table 2: Solvent physical properties. All taken from published data and estimation methods [17] at $20^{\circ} \mathrm{C}$. 